\title{
A CASE OF PERMANENT BLINDNESS DUE TO TOXAEMIA OF PREGNANCY*
}

BY

\author{
L. B. Somerville-LARge \\ Dublin, Eire
}

THE fact that permanent blindness is such a rare complication in the toxaemia of pregnancy has prompted me to set the following case on record.

I can find no account of permanent blindness resulting from pregnancy in the records of the Rotunda Hospital, Dublin. Certainly no case has occurred in the last 73,572 pregnancies covered by the hospital (1935-48), and three Masters who held office before 1935 (Dr. Fitzgibbon, 1919-26 ; Dr. Bethel Solomons, 1926-33, and Dr. Davidson, 1932) have kindly allowed me to state that during their periods of mastership no case of permanent blindness occurred. Thus, this case appears to be the first in over 150,000 births. Since the classification of what constitutes " toxaemia of pregnancy" has undergone modification during the last 30 years, it would be valueless to give statistics. Any marked degree of permanent reduction in sight after toxaemia of pregnancy has been an unusual occurrence in the Rotunda Hospital. No mother in these last 73,572 births has required blind assistance as a result of her pregnancy.

An investigation of the literature has produced only one case of permanent blindness due to pregnancy toxaemia. A 30-yearold woman had a transient loss of sight on her third pregnancy, lost the sight of one eye (with marked diminution in the other) on her fourth pregnancy, and went totally and permanently blind on the fourth day after the birth of her fifth child. Six years later she developed presenile dementia. She was examined generally and ophthalmologically seven weeks after the birth of her fourth child, and again two years after going blind following her fifth pregnancy. On both occasions the urine showed no albumen and exhaustive examination of the central nervous system revealed no abnormality. There is no record of urine analysis or blood pressure. Her blindness was caused by post-neuritic atrophy.

\section{Case Report}

History.-The patient, 26 years of age, was admitted (January, 1949) to the Rotunda Hospital in the 35 th week of her sixth pregnancy. Her four previous pregnancies had been normal full-term deliveries. In none had she suffered from

* Received for publication March 7, 1950. 
toxaemia, or had any visual symptoms, or transient loss of sight. She had never had any serious illnesses (measles in childhood, appendicectomy two years previously). Her only complaint was intermittent headaches for some years.

General Condition.-She was admitted as an emergency with the diagnosis of "pre-eclampsia". Her general condition was described as "fairly good". She was conscious and rational. There was no generalized cedema. Blood pressure was 220/170; urine showed "albumen abundant"; temperature $98^{\circ}$; pulse 106. At no time before or after delivery did she have convulsions. Caesarean section was carried out the day after admission, and a live male baby of $4 \frac{1}{2} \mathrm{lbs}$. was delivered. The baby was healthy, and has continued to thrive. After operation the patient developed paralytic ileus and became acutely ill. She remained in hospital for over three months, and on discharge was reasonably well. The diagnosis was toxaemia of pregnancy.

Ophthalmic Condition.- The patient stated that two weeks prior to admission her sight had become blurred, and that for the last two days it had begun to fail rapidly. No previous loss of sight had nccurred during pregnancy.

On admission the right pupil was inactive to light; the left was active. Vision in the right eye was reduced to no perception of light and in the left to counting fingers at a distance of one foot. Both fundi showed marked oedema of the disks and surrounding retina with haemorrhages and cotton wool exudates. There was severe generalized angiospasm. The retina in the lower part of each fundus was detached, shallow in the lower nasal quadrant but deep and globular in the lower temporal quadrants. Eight days later the detachments were a good deal less, the retinopathy was unchanged, but vision was now reduced in both eyes to no perception of light.

Three weeks after admission the ocular condition was:

R.E., disk and surrounding area of retina less oedematous. Vessels still very small. Fewer haemorrhages and exudates. Detachment small, 5 to 8 o'clock only. Pupil dilated and inactive to light, active with convergence. Vision, no perception of light.

L.E., very little blurring of disk margin. Disk paler than R. Fewer haemorrhages and exudates. Scattered pigmentation appearing in fundus at site of old haemorrhages and exudates. Detachments much smaller, confined only to the lower and outer quadrant. Vessels still very small. Pupil widely dilated and inactive to light, active with convergence. Vision, no perception of light.

On discharge the condition was: fixed mydriasis. No retinal detachment. Both optic disks showed an advanced degree of secondary atrophy with gross constriction of vessels. The retinal arteries were scarcely visible. There was no perception of light in either eye.

Diagnosis.-A diagnosis of bilateral total transverse neuritis can be made with certainty in this case. The neuritis had occurred near the nerve head, thereby producing papilloedema and, as is usual in such cases, resulting in secondary atrophy.

\section{Discussion}

The interest from the purely ophthalmological view-point lies in the aetiology of this rare condition. In an attempt to determine this the patient was admitted twelve months later (January, 1950) to the Royal City of Dublin Hospital, where Prof. Synge undertook a complete investigation.

The following tests were carried out: Urine analysis; blood pressure; uroselectan; cystogram; $X$ ray of sinus and pituitary; and full investigation of the central nervous system. Apart from the blood pressure and urine analysis nothing abnormal was found. The blood pressure varied between $225 / 170$ and $235 / 170$. The urine contained albumen, pus, and an occasional hyaline cast. Blood urea was $25 \mathrm{mg}$. per cent. The Ascheim-Zondek test for pregnancy was positive, and it was considered 
that she was some two months pregnant. Ophthalmological examination showed bilateral fixed mydriasis, advanced secondary optic atrophy, and severe generalized angiospasm with gross notching of the arteriovenous crossings. Vision in the right eye was no perception of light, but in the left there was a definite occasional light perception in a small area downward and outward.

The toxin, if toxin it be, of pregnancy toxaemia remains unknown. It must be recollected too, that the existence of a toxin is challenged by many investigators. Thus Falkiner (1950), following his work on the placenta, considers the condition to be "secondary to vascular disturbances consequent on arteriolar spasm." In a routine series of 204 toxaemia cases that I have investigated in the Rotunda Hospital, 43.6 per cent. showed either localized or generalized angiospasm of the retinal arteries, Pickering (1950) on the other hand has never seen spasm of the retinal arteries in pregnancy toxaemia. The view of Bastiaanse (1950) is that the toxaemia is related to an absolute or relative insufficiency of the blood supply to the placenta. All are agreed that the fundamental clinical finding in toxaemia is high blood pressure, and that the kidney dysfunction is secondary. Retrobulbar neuritis producing transient loss of sight, often very dramatic but unassociated with fundus changes, is relatively common. Full vision normally returns.

We know that total occlusion of the central retinal artery (whether by spasm or embolism) produces sudden and deep blindness; and also that if the occlusion persists long enough, the blindness becomes permanent. These arterial blocks usually take place in the region of the cribriform plate, and may therefore be considered as too far forward in the nerve to produce papilloedema. The case under review exhibits extreme generalized angiospasm of the ophthalmoscopically visible retinal arteries, It is suggested that the papilloedema which was present in this case could follow a severe spasm of ${ }^{\wedge}$ the entire retinal artery. The spasm by its persistence, would result in blindness and secondary optic atrophy. There is a possibility that oedema of the brain by producing increased intracranial pressure could account for the bilateral papilloedema that I have observed in severe toxaemia cases, always associated with eclampsia, gross generalized oedema, and retinal detachments. The papilloedema clears with the subsidence of the general oedema and improvement of the condition. Angiospasm would also explain the transient loss of vision in pregnancy toxaemia. Indeed it is difficult to account for the transient haemianopia which is by no means a rare concomitant of toxaemia, by any other hypothesis. Angiospasm as a cause of optic atrophy would also fall in well with the findings of Mooney and 
McConnell (1949). These investigators consider that the optic atrophy found in space-occupying lesions in the region of the carotid tree results, not from direct pressure on the nerve or chiasma, but from interference with their blood supply.

\section{Conclusion}

This therefore must be considered a case in which total transverse neuritis resulted as a concomitant to toxaemia of pregnancy in an otherwise healthy woman. The unusual general features were the absence of convulsions or severe oedema and the fact that neither transient blindness nor toxaemia had occurred in previous pregnancies.

It is suggested that the retrobulbar neuritis in this case is the result of angiospasm, and that angiospasm also plays a dominant rôle in other ocular conditions resulting from the toxaemia of pregnancy.

My thanks are due to Dr. O'Donel Browne, Master of the Rotunda Hospital, who kindly permitted me to publish this case, to Dr. Ninian Falkiner, late Master of the Rotunda Hospital, who added his advice on this case to much already given, to the three previous Masters, Dr. Gibbon FitzGibbon, Dr. Bethel Solomons and Dr. Andrew Davidson, who all gave me assistance and advice, and to Dr. Desmond Douglas who made the first records of this case and has subsequently followed it up with me.

\section{REFERENCES}

Bastiannse, van B. (1950).-Brit. med. J., 1, 243.

FALKINER, N. (1950). Ibid., 1, 242.

Mooney, A. J. and MCConnel, A. A. (1949). J. Neurol. Neurosurg. Psychiat., 12, 205.

Pickering, G. W. (1950). Brit. med. J., 1, 243.

Weigelin, S. (1908). Arch. Augenheilk., 61, 1. 